\title{
Modes of Seeing: Digitized Photographic Archives and the Experienced User
}

\author{
Paul Conway
}

\begin{abstract}
A b s tract
Digitization practice in archives and libraries is now generating digital content and associated tools and practices that are transforming the relationships among archivists, users, and archival collections. The transformative nature of digitization derives in part from the power of the complex technologies to represent images and facilitate their use. This article explores how experienced, but for the most part nonacademic, users see the visual, material, and archival properties of digitized photographic archives while undertaking innovative and insightful projects that push the boundaries of visual interpretation. The study is a qualitative investigation involving independent case studies of seven people who have extensive experience using the photographic archives preserved by the Library of Congress. This article contextualizes the research in a range of literatures, summarizes the research methodology, and presents findings from in-depth interviews that focus on how visually experienced users choose digitized photographs for inclusion in a given project. By understanding these "modes of seeing" the contemporary digitized visual archives, archivists are in a better position to understand the representational implications of their digitization processes.
\end{abstract}

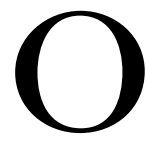

ver time and with increasing confidence, cultural heritage organizations are transforming large portions of their photographic archives by digitizing original prints and negatives, transcribing and augmenting metadata, and delivering the combined products for use. Seamus Ross notes that large-scale digital libraries are simultaneously mechanisms for delivering digital surrogates of archival holdings and new archival collections in

\section{(C) Paul Conway.}

The research reported here is funded in part by the National Science Foundation (IIS-0733279). The author is grateful for the support of the staff of the Library of Congress's Prints and Photographs Division, especially Barbara Orbach Natanson. Ricardo Punzalan provided valuable assistance in designing and setting up the participant interviews. 
their own right that reflect the decisions that digital curators make throughout the digitization process. ${ }^{1}$ Today's ubiquitous digitization activities began simply enough as experiments with new technologies. After nearly twenty years, digitization practice has become a transformative process that reaches all aspects of the archival enterprise. Even when archival organizations choose to minimize their use of digitization tools, users increasingly are demanding remote access to archival collections, perhaps sidestepping archives that do not have a significant online presence. The transformative nature of digitization restructures the value and meaning that users extract from large collections of digitized photographs. Although meaning originates with the source, the ways that users see photographs online may be influenced by their encounters with the digital surrogates themselves, which carry with them a mix of visual, technological, and archival properties.

Community-based practices developed by tightly circumscribed but overlapping networks of technical experts guide the multibillion dollar investment by archives, libraries, and museums to build digital collections from photographic and other cultural resources. ${ }^{2}$ Virtually no research, however, has explored the relationship between building and using digital image archives. ${ }^{3}$ Tefko Saracevic reviews a decade of digital library evaluation studies and finds that "more often than not, digital library users and digital libraries are in an adversarial position." 4 Saracevic assesses more than eighty evaluation studies and finds only three that study image-based collections, all of which focus on retrieval effectiveness. ${ }^{5}$ Use studies conducted at Pennsylvania State University ${ }^{6}$

\footnotetext{
${ }^{1}$ Seamus Ross, "Digital Preservation, Archival Science and Methodological Foundations for Digital Libraries," Keynote Address at the 11th European Conference on Digital Libraries, Budapest, 17 September 2007.

${ }^{2}$ Paul Conway, "Best Practices for Digitizing Photographs," Proceedings of Archiving 2008, IS\&T, Bern, Switzerland, 24-26 June 2008.

${ }^{3}$ Ching-chi Chen et al., "Digital Imagery for Significant Cultural and Historical Materials," International Journal of Digital Libraries 5 (2005): 275-86.

${ }^{4}$ Tefko Saracevic, "How Were Digital Libraries Evaluated?", paper first presented at the DELOS WP7 Workshop on the Evaluation of Digital Libraries (2004), 9, available at http://www.scils.rutgers. edu/ tefko/DL_evaluation_LIDA.pdf, accessed 17 May 2010.

${ }^{5}$ I. J. Cox et al., "The Bayesian Image Retrieval System, PicHunter: Theory, Implementation and Psychophysical Experiments," IEEE Transactions on Image Processing 9 (2000): 20-37; J. W. Han and L. Guo, "A Shape-Based Image Retrieval Method Using Salient Edges," Signal Processing: Image Communication 18 (2003): 141-56; G. J. F. Jones and A. M. Lam-Adesina, "An Investigation of MixedMedia Information Retrieval," Research and Advanced Technology for Digital Libraries: Proceedings of the Second European Conference, ECDL'02 (2002): 463-78.

${ }^{6}$ Henry Pisciotta et al., "Penn State Visual Image User Study," Portal: Libraries and the Academy 5 (January 2005): 33-58.
} 
M O D E S

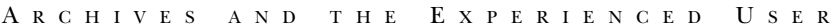

and the University of California, Berkeley, ${ }^{7}$ provide important demographic insights but reach no conclusions about how users find meaning in the images they select. In a separate exhaustive review of empirical studies regarding the concept of "relevance," Saracevic identifies only one study carried out in image databases, ${ }^{8}$ a study that uses the Library of Congress's American Memory collections as a test bed. ${ }^{9}$

Theoretical Context

Building collections of photographs through digitization is fundamentally a process of representation, a far more interesting and complex phenomenon than merely copying photographs from one medium to another. W. J. T. Mitchell defines representation as a mediated relationship using signs or symbols between the maker and the viewer of one object that stands for another. According to Mitchell, "Representation is always of something or someone, by something or someone, to someone." ${ }^{10}$ In Mitchell's theories, which are derived from his scholarship at the nexus of the word and image, representation practice is fraught with the potential for communication problems that range from misinterpretation and misunderstanding to falsehood and forgery. "As soon as we begin to use representations in any social situation-to claim, for instance, that this dab of paint represents the fact that this stone is in that place and looks like this-then representation begins to play a double role, as a means of communication which is also a potential obstacle to it," asserts Mitchell. ${ }^{11}$ When considered as a form of representation, digitization of archival photographs comprises a means of communication between image and user in which the archivist, as digitizer, system builder, and interface architect, plays a fundamental mediating role.

In his exploration of visual representation, Mitchell distinguishes between two concepts: image and picture. A picture is "a material object, a thing you can burn or break," whereas "an image is what appears in a picture and what survives

\footnotetext{
${ }^{7}$ Diane Harley et al., Understanding the Use of Digital Collections: A Focus on Undergraduate Education in the Humanities and Social Sciences, Center for Studies in Higher Education, University of California, Berkeley (2006); Diane Harley et al., Use and Users of Digital Resources: A Focus on Undergraduate Education in the Humanities and Social Sciences (Berkeley: Center for Studies in Higher Education, 2006), available at http://www.escholarship.org/uc/item/8c43w24h, accessed 17 May 2010.

${ }^{8}$ Youngok Choi and Edie M. Rasmussen, “Users' Relevance Criteria in Image Retrieval in American History," Information Processing and Management 38 (2002): 695-726.

9 Tefko Saracevic, "Relevance: A Review of the Literature and a Framework for Thinking on the Notion in Information Science. Part III: Behavior and Effects of Relevance," Journal of the American Society for Information Science and Technology 58 (2007): 2126-44.

${ }^{10}$ W. J. T. Mitchell, "Representation," in Critical Terms for Literary Study, $2^{\text {nd }}$ ed., ed. Frank Lentricchia and Thomas McLaughlin (Chicago: University of Chicago Press, 1995), 11-12.

${ }^{11}$ Mitchell, "Representation," 12.
} 
its destruction-in memory, in narrative, and in copies and traces in other media." 12 In a similar vein, Robert Wicks draws attention to the filtering that occurs in the transition between image and picture.

Actual photographs express ideas about their subject in a fashion which...we may call "masking." In this manner, an object is manifested to us in the photograph, which, at the same time, certain visual qualities of the object are photographically filtered out from and/or other features are added to the object's appearance. ${ }^{13}$

Wicks's conclusion extends to the digitization of photographs, whereby a sequence of scanning and postscan enhancements transforms the visual and material characteristics of the source photograph. ${ }^{14}$ The visual properties of a digitized photograph constitute a representation of a representation, in which the original scene, "seen" through the camera's lens, makes its way to the contemporary viewer through time, space, and technology.

Scholars from a wide variety of disciplines are beginning to explore how theories of visual representation bear upon the use of digital collections of photographs. Archivist Joanna Sassoon largely sees diminished meaning ("an ephemeral ghost") through digitization, ${ }^{15}$ whereas literary critic Mitchell finds potential transcendence. "In a world where the very idea of the unique original seems a merely nominal or legal fiction, the copy has every chance of being an improvement or enhancement of whatever counts as the original." 16 Archivist Lilly Koltun emphasizes that a digitized photograph "leaves behind another originating document whose disposal or retention can inspire other archival debates focused around original attributes and meanings not 'translated' into, even distorted by, the new medium." 17 Museum studies theorist Fiona Cameron argues that digitized photographs are "digital historical objects" in their own right, "separate from any referent, and as an entirely new creative project the materiality argument can no longer be given pre-eminence." 18 Skeptics and

${ }^{12}$ W. J. T. Mitchell, "Visual Literacy or Literary Visualcy?," in Visual Literacy, ed. James Elkins (London: Taylor and Francis, 2007), 16.

${ }^{13}$ Robert Wicks, "Photography as a Representational Art," British Journal of Aesthetics 29 (Winter 1989): 9.

${ }^{14}$ Paul Conway, "Building Meaning in Digitized Photographs," Proceedings of the Chicago Colloquium on Digital Humanities and Computer Science 1 (2009).

${ }^{15}$ Joanna Sassoon, "Photographic Materiality in the Age of Digital Reproduction, in Photographs, Objects, Histories, ed. Elizabeth Edwards (London: Routledge, 2004), 199.

${ }^{16}$ W. J. T. Mitchell, "The Work of Art in the Age of Biocybernetic Reproduction," Modernism/Modernity 10 (2003): 497.

${ }^{17}$ Lilly Koltun, "The Promise and Threat of Digital Options in an Archival Age," Archivaria 47 (Spring 1999): 124.

${ }^{18}$ Fiona Cameron, "Beyond the Cult of the Replicant: Museums and Historical Digital Objects Traditional Concerns, New Discourses," in Theorizing Digital Cultural Heritage: A Critical Discourse, ed. Fiona Cameron and Sandra Kenderdine (Cambridge, Mass.: MIT Press, 2007), 68. 
M O D E S

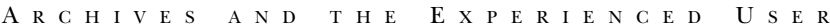

enthusiasts on both sides of this argument stake their claims without explicit evidence about user needs and user expectations regarding visual, material, or archival properties of the digital surrogates.

Technologies of digital representation-such as scanning, image processing, and delivery through a graphical user interface-radically transform the communication paradigm that is fundamental to representation. Through their theory of remediation, Jay David Bolter and Richard Grusin provide a mechanism for understanding how the technical properties of digitized photographs relate to the user's definition of meaning. Remediation is a culturally driven desire both "to multiply its media and to erase all traces of mediation: it wants to erase its media in the very act of multiplying technologies of mediation." 19 Evidence of remediation of photographic content through new technologies is found in the repurposing of digitized photographs in interactive video games ${ }^{20}$ and, most recently, in the wide distribution of large collections of digitized photographs in social network sites such as Flickr. ${ }^{21}$ Remediation theory postulates that those who build digital collections seek "technological transparency," whereby viewers of digital surrogates are able to establish the same relationship with the image as they are able to have with the original. "But of course this is never so," argue Bolter and Grusin. "The computer always intervenes and makes its presence felt in some way."22 The representation of archival photographs through digitization technologies carries the potential for contradictory and confusing messages for users, where the distinction between old and new media is lost in the technical minutia of the digitization process itself.

Archivists increasingly are becoming attuned to the implications of digital representation for archival theory. In introducing a paper on the creation of a Web-based map archive, Joan Schwartz points toward a tension between the views of theorists and practitioners regarding digitized materials:

Many professional archivists would not view [a digitized assembled collection] as "an archive" in the strictest "organic" sense of the word; however, it is the very use of the word that points to the discomforting specter of "two solitudes" with almost mutually exclusive bodies of professional writing: "the archive" as understood by academics, cultural critics, and computer aficionados, and the "real world of archives" as practiced by archivists with their own set of principles and practices. ${ }^{23}$

\footnotetext{
${ }^{19}$ Jay David Bolter and Richard Grusin, "Remediation,” Configurations 4 (1999): 312.

${ }^{20}$ Cindy Poremba, "Point and Shoot: Remediating Photography in Gamespace," Games and Culture 2 (January 2007): 49-60.

${ }^{21}$ Library of Congress' Photostream, "The Commons," Flickr, available at http://www.flickr.com/ photos/library_of_congress/, accessed 17 May 2010.

${ }^{22}$ Bolter and Grusin, "Remediation," 339.

${ }^{23}$ Joan M. Schwartz, “'Having New Eyes’: Spaces of Archives, Landscapes of Power,” Archivaria 61 (Spring 2006): 12
} 
Although archivists are discussing their roles as agents in the construction of history and societal knowledge, ${ }^{24}$ explicit discussion of the archival properties of digital surrogates has not yet been published in the archival literature.

Geoffrey Yeo's recent work on the archival record contains clues about the archival nature of digital surrogates. He poses a theory that some types of archival records-for example, photographic archives-exist as "boundary objects" at the margins of core archival constructs. In adapting Susan Leigh Star's pioneering work on the multiple social values of museum collections, ${ }^{25}$ Yeo notes that the archival nature of boundary objects varies according to the uses to which they are put. In his example of the historical photographic archive, Yeo notes that "a visual item could be interpreted as a record, a photograph, an artifact of aesthetic design, a symbolic object, and an economic asset. Each community brings its own perspective to the table." ${ }^{26}$ Yeo's theory, when applied to digitized photographs, postulates that boundary objects constructed from archival sources carry with them their archival nature and exist as "persistent representations" of an event or activity at one or multiple points in time and space. ${ }^{27}$ The extent to which users interpret and trust the archival properties of boundary objects such as digitized photographs is an open question.

In the creation of digital surrogates of archival photographs, trust likely functions on multiple levels. Abby Smith locates trust in the organization that builds and maintains digitized collections. "The only reason that we expect [an] image to be a truthful representative of the original is that we can rely on the integrity of the institution that has mounted the files and makes them available to us." 28 Luciana Duranti and the many archivists who have contributed to the InterPARES initiative lodge trust at the level of the individual record and its significant components, defining integrity as a function of documented authenticity and, most especially, reliable reproduction methods. "Degree of completeness and degree of control of the procedure of creation are the only two factors that determine the reliability of records." 29 These claims for archival trust are made by archivists acting as proxies for users, whose perspectives on the archival nature of digital surrogates are not well understood.

${ }^{24}$ Tom Nesmith, "Seeing Archives: Postmodernism and the Changing Intellectual Place of Archives," American Archivist 65 (Spring/Summer 2002): 41.

${ }^{25}$ Susan Leigh Star and James R. Griesemer, "Institutional Ecology, 'Translations' and Boundary Objects: Amateurs and Professionals in Berkeley's Museum of Vertebrate Zoology, 1907-39," Social Studies of Science 19 (August 1989): 393.

${ }^{26}$ Geoffrey Yeo, "Concepts of Record (2): Prototypes and Boundary Objects," American Archivist 71 (Spring/Summer 2008): 131.

${ }^{27}$ Yeo, “Concepts of Record (2)," 129.

${ }^{28}$ Abby Smith, Why Digitize? (Washington, D.C.: Council on Library and Information Resources, 1999), 5 .

${ }^{29}$ Luciana Duranti, "Reliability and Authenticity: The Concepts and Their Implications," Archivaria 39 (1995): 6 . 
M O D E S

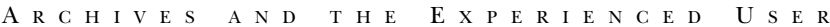

\section{Research Questions, Methodology, and Data Analysis}

Given the relative dearth of research on the actual use of digitized photographic archives, this research is necessarily exploratory in character. The project is grounded in a theory that the digitization of photographs is a process of representation in which material artifacts are remediated as new artifacts with properties derived from the original sources. Against this theoretical backdrop exists a need to define how the visual, technical, and archival properties resonate with users within the communication structure of representation, a structure that places a computer screen and graphical user interface between the intention of the digitizer and the goals of those who need surrogates for specific, product-oriented projects.

Adopting Mitchell's constructive distinction between a picture (what you can break) and an image (what appears in a picture and survives in memory), this research explores the circumstances under which the materiality of the artifact resonates intellectually and emotionally with the user who must make both global and particular decisions in a sea of digital possibilities. If collections of digital surrogates hold archival properties, as Yeo, Nesmith, and others postulate, then a further question arises over the extent to which users treat digital surrogates as archives (pictures), as opposed to treating them primarily as convenient memory devices (images) accessible more conveniently and cost effectively than their sources.

Q1. Seeing Images: How do the visual aspects of digitized photograph archives influence the choice of images for a given purpose?

Q2. Seeing Pictures: What is the relative importance of the technical characteristics of digitized photograph archives in determining the choice of images for a given purpose?

Q3. Seeing Archives: To what extent do the archival properties of digitized photograph archives and the underlying photographic sources influence the choice of images for a given purpose?

This research mines the knowledge and experience of visually oriented researchers whose expertise with digitized photographs is the foundation of their individual projects. The definition of "expertise" is based on the traditional terminology of medieval craft guilds. An expert is

the distinguished or brilliant journeyman, highly regarded by peers, whose judgments are uncommonly accurate and reliable, whose performance shows consummate skill and economy of effort, and who can deal effectively with rare or "tough" cases. Also, an expert is one who has special skills or knowledge derived from extensive experience with sub-domains. ${ }^{30}$

\footnotetext{
${ }^{30}$ Robert Hoffman et al., "Eliciting Knowledge from Experts: A Methodological Analysis," Organizational Behavior and Human Decision Processes 62 (May 1995): 132.
} 
This definition acknowledges that expertise is socially constructed and validated through community judgment. Expertise demands high levels of technical skill and efficiency, as well as the capability to recognize and deal with exceptions to a rule. The definition incorporates focused experience as one of several components, but not necessarily the most important one.

Experts marshal experience more effectively than novices. John Bransford's research on learning highlights the fundamental differences. "Experts have acquired extensive knowledge that affects what they notice and how they organize, represent, and interpret information in their environment." ${ }^{31}$ Experts have mastered their subject domain and can find and retrieve facts and information "with little attentional effort," but may not be able to teach others or convey their deep understandings other than in the specific products they produce. In his study of the differences between novice and expert historians in the use of textual and pictorial documents, Samuel Wineburg concludes that experts have acquired the ability to construct a "context-specific schema" tailored to a specific event or problem-situation. ${ }^{32}$ Even more tellingly, Wineburg's research, corroborated by Helen Tibbo and others who have studied experts and the use of archival resources, suggests that experts approach textual and visual records with more sweeping ways of knowing and thinking about evidence. ${ }^{33}$ Experts have more nuanced ways of seeing the evidence in the archival record, not simply more experience using archives.

In his review of two decades of empirical research on extracting knowledge from experts, Robert Hoffman concludes that a combination of documentation analysis, task analysis, and thinking-out-loud protocol analysis is the most effective overall approach to eliciting knowledge from experts. ${ }^{34}$ This research project adapts this strategy by conducting two-stage, semistructured interviews with experienced users, supplemented by an independent analysis of the content and context of the source materials users consulted for specific projects with defined outcomes. The locus of research is individuals who have made significant use of digitized photographs provided by the Library of Congress.

\footnotetext{
${ }^{31}$ John D. Bransford, Ann L. Brown, and Rodney R. Cocking, eds., How People Learn: Brain, Mind, Experience and School, expanded edition (Washington, D.C.: National Academy Press, 2000), 31.

${ }^{32}$ Samuel S. Wineburg, "Historical Problem Solving: A Study of the Cognitive Processes Used in the Evaluation of Documentary and Pictorial Evidence," Journal of Educational Psychology 83 (March 1991): 84.

${ }^{33}$ Helen R. Tibbo, "Primarily History in America: How U.S. Historians Search for Primary Material at the Dawn of the Digital Age," American Archivist 66 (Winter 2003): 9-50.

${ }^{34}$ Hoffman et al., "Eliciting Knowledge from Experts," 140.
} 
M O D E S O F

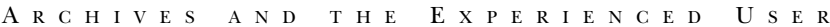

\section{Research Context}

The Library of Congress distributes one of the largest collections of digitized cultural heritage resources in the world. The two principal digital collections are the American Memory historical collections and the Prints and Photographs Division Online Catalog. American Memory had its origins in the early 1990s as the National Digital Library Program. It now unifies search and browse functions across nine million items from 138 discrete physical collections, twenty-three of which are not part of the Library of Congress's physical holdings. ${ }^{35}$ The Prints and Photographs Division (PPD) holds more than fourteen million items (photographs, prints, architectural documentation). The PPD Online Catalog provides access to approximately 1.2 million digitized images. ${ }^{36}$ It includes textual descriptions for about half of the total holdings (some images are cataloged as groups and some catalog records do not link to digitized items). American Memory, as the name implies, focuses its digital resources on American history and culture, whereas the digital resources of the Prints and Photographs Division have an international reach. The two large digital collections overlap significantly. ${ }^{37}$

Library of Congress digital programs have served as a test bed for research for over a decade. Among the best and most influential studies are those of Gary Marchionini and his research team, who conducted extensive and multifaceted usability research in the mid-1990s as part of the interface design for American Memory. ${ }^{38}$ Youngok Choi and Edie Rasmussen used American Memory to test search query formulation. ${ }^{39} \mathrm{H}$. I. Xie examined the attitudes and perceptions of users toward a set of digital library evaluation criteria. ${ }^{40}$ Marija Dalbello deconstructed leadership behavior in the development of the National Digital Library Program as a case study in the social construction of technology. ${ }^{41}$ These studies treat the digital content of American Memory as a fixed and holistic dataset, and

${ }^{35}$ Library of Congress, American Memory, available at http://memory.loc.gov/ammem/index.html, accessed 4 April 2010.

${ }^{36}$ Library of Congress, Prints and Photographs Online Catalog, available at http:/ /www.loc.gov/pictures, accessed 4 April 2010.

${ }^{37}$ Carolyn Y. Arms, "Getting the Picture: Observations from the Library of Congress on Providing Online Access to Pictorial Images," Library Trends 48 (Fall 1999): 379-409.

${ }^{38}$ Gary Marchionini, Catherine Plaisant, and Anita Komlodi, "Interfaces and Tools for the Library of Congress National Digital Library Program," Information Processing and Management 34 (September 1998): 535-55.

${ }^{39}$ Youngok Choi and Edie M. Rasmussen, "Users' Relevance Criteria in Image Retrieval in American History," Information Processing and Management 38 (2002): 695-726.

${ }^{40}$ H. I. Xie, "Users' Evaluation of Digital Libraries (DLs): Their Uses, Their Criteria, and Their Assessment," Information Processing and Management 44 (2008): 1346-73.

${ }^{41}$ Marija Dalbello, “A Phenomenological Study of an Emergent National Digital Library, Part I: Theory and Methodological Framework," Library Quarterly 75 (October 2005): 391-420; "Part II: The Narratives of Development," Library Quarterly 76 (January 2006): 28-70. 
none seeks to understand the potential relationship between user behavior and the characteristics of the visual content itself. The study reported here assumes that the Library of Congress's online collections are enabling mechanisms for unknown communities of users. Focusing on large collections of digitized photographs from a single repository in part helps control for variations across systems in three areas that are out of scope for this research: interface design; variance in digital imaging processes; and dissonant metadata models.

Identification of Study Group

The initial request to the Library of Congress asked curators to identify potential participants for an independent study, based on the following general criteria: 1) significant use of the digitized photographic holdings of the Library of Congress within the past eighteen months (2007-2008); and 2) work that has recently produced a tangible product (book, scholarly article, motion picture, complex website, online exhibition, etc.) likely to be credited in part to the Library of Congress. The investigator identified seven individuals from an initial list of twenty names provided by the curators of the Prints and Photographs Division. The selection of interview participants was not random but rather reflected the knowledge of the PPD curators about ongoing or recently completed projects, combined with the willingness and availability of prospective study participants. The curatorial staff of the PPD contacted potential participants by email and provided an overview of the research project prepared by the investigator. The investigator responded to questions about the research project by email and obtained permission for a first-phase interview.

\section{Participants, Projects, Products}

The seven participants varied widely in terms of demographic, educational, and occupational characteristics. Three were female; four were male. Their ages ranged from thirty to sixty-seven. The participants worked and lived east of the Mississippi River in five separate communities. All seven were college graduates, in disciplines that encompassed the arts and humanities, social science, and business. Two obtained master's degrees, and one was a doctoral student at the time of the interview. None of the participants were trained as archivists, although two individuals had experience working as paraprofessionals in one or more archives. Only one of the seven had an educational background in photography; all participants characterized themselves as self-taught in the areas of their research. All but one of the participants were nonacademic in their orientation toward their work, in that their approach to research and visual investigation generally lacked an overt theoretical perspective. 
M O D E

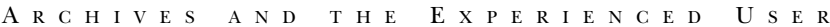

Table 1 presents summary information on the context of products and projects on which the interviews focused. The products included four books, a dissertation, a complex and dynamic website, and a database for a membership organization. For their projects, participants used digitized photographs delivered from either the American Memory collection (AmMem) or the online catalog of the Prints and Photographs Division (PPD). Each of the five collections consulted is discrete within its particular delivery system. The Civil War Photographs collection is available through interfaces to both the American Memory and the PPD databases. The Turkestan Album and the photographs from the National Child Labor Committee (NCLC) are available in digital form only through the PPD online catalog. Portions of the Farm Security Administration/Office of War Information collection (FSA/OWI) are distributed through the American Memory interface, but the entire digitized collection is fully available only through the PPD interface. Finally, the Bain photograph collection is fully available digitally through the PPD interface and selectively through the American Memory interface.

Table I. Projects and Products

\begin{tabular}{l|l|l|l|l|l}
\hline & Project & Collection & Database & Product & Stage in 2009 \\
\hline PI & US Civil War photographers & Civil War & AmMem & Book & Done \\
\hline P2 & Russian colonialism & Turkestan & PPD & Dissertation & In progress \\
\hline P3 & Child labor practices & NCLC & PPD & Website & Ongoing \\
\hline P4 & Depression-era music & FSA/OWI & PPD & Book & Done \\
\hline P5 & Biography of photographer & FSA/OWI & PPD & Book & In progress \\
\hline P6 & Depression-era photo story & FSA/OWI & AmMem & Book & Done \\
\hline P7 & Baseball history & Bain & PPD/AmMem & Database & Ongoing \\
\hline
\end{tabular}

Interview Procedures and Analysis

A doctoral student research assistant conducted seven initial telephone interviews of approximately forty-five minutes in duration. Each interview was recorded and the results transcribed. The phase-one interview introduced the research project, obtained background information on the training and experience of the participant, and identified one or more potential ongoing or recently completed projects by the interview participant. Sufficient detail on each user's project was obtained to permit the investigator and the research assistant to assemble and analyze extant documentation on each project. ${ }^{42}$

${ }^{42}$ Paul Conway, "The Image and the Expert User: A Qualitative Investigation of Decision-Making," Proceedings of ISE'T's Archiving 2009, Arlington, Virginia, 4-7 May 2009, 142-50. 
The investigator conducted individual face-to-face interviews with each of the seven participants at their residence or office, chosen by them as the location where they most frequently used the digital images. Before the on-site interview, each participant was provided with a one-page general interview protocol (see Appendix 1) that identified the topical areas and general order of the interview. Each interview proceeded in a semistructured fashion through three major components: 1) self-assessment of expertise with photographic materials and digitized photographs; 2) overall decision-making strategies for the identified project; and 3) an assessment of the visual, technical, and archival properties of individual digitized photographs selected for inclusion in the project. Interviews varied from 1.5 to 4.5 hours in length. Each interview was recorded and the results transcribed, yielding textual data of 139,256 words on 309 pages.

Analysis proceeded in three stages: 1) the immediate creation of a journal entry with contextual information not captured in the recordings and any numbers or proper nouns from notes to aid the interview transcription process; 2) the assembly of data from the interview instruments; and 3) the qualitative analysis of interview transcripts using the grounded theory method. Grounded theory analysis is designed to extract systematic knowledge on research problems for which the underlying theory is underdeveloped.$^{43}$ The term "grounded" refers to the process of developing testable hypotheses from the interview data itself, rather than using interview data to test pre-established theories.

Grounded theory analysis identifies patterns of meaning through the iterative, line-by-line extraction of concept terms from interview transcripts. This method is particularly useful for semistructured interviews during which participants use their own descriptive terms, instead of being prompted by the wording of questionnaires or other discussion guides. Emergent theoretical constructs are identified, via the interview transcripts, from the participants' own descriptions of their experience and expertise. The outcome of grounded theory analysis has no predictive power for the general population of the users of the Library of Congress or any other large digital collection. Instead the interviews constitute raw material to develop a theory of the use of visual archives. The power of the research derives from the analytical method. Given the relative weaknesses of visual-based user research, grounded theory provides a great degree of analytical flexibility.

\section{Findings: Modes of Seeing}

Seven highly experienced visual researchers provided ample raw material for constructing a multifaceted theory of how digitized photographic archives

\footnotetext{
${ }^{43}$ Kathy Charmaz, Constructing Grounded Theory: A Practical Guide through Qualitative Analysis (Thousand Oaks, Calif.: Sage, 2006).
} 
M O D E S

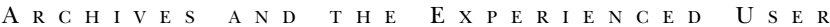

yield knowledge through use. The findings mine interview transcripts for evidence of three distinctive ways of seeing digitized content. The first way involves seeing digitized photographs as objects whose visual content is their primary value. Adapting Mitchell's distinction, experienced users are facile in seeing an image as what appears in a picture and survives its digitization. ${ }^{44}$ The second way of seeing engages the material properties of the original source photograph through the intermediary power of digitization-the surrogate as picture-or, in Mitchell's view, "a material object, a thing you can burn or break." In a third way of seeing, visually oriented researchers experience the surrogate directly as the archival record, as what Yeo and Star call "boundary objects," often without reference to the source, endowed with archival properties as preserved and trustworthy.

\section{Se e ing I mages}

Experienced users see images for the data they provide the relevance of which is determined by the user's particular field of view. The value of an image is also seen to reside in the emotions that the image elicits from the viewer. Digitized archival photographs, transmitted seamlessly from archive to home or office, have a particularly strong emotional power that text-based records often lack, even those with intense symbolic value.

Field of view

An image is simultaneously a mix of visual data elements (a hand, a tin cup, a distant skyline), a whole composition, and a piece of a puzzle that exists in time and space beyond the border. Participants saw the visual content of images from one or more of these perspectives and placed demands on the visual content of the digitized photographs based upon a particular field of view.

Participant 1 was driven by visual knowledge obtained from mining very high resolution digital images of original camera negatives, in this case a stereographic negative approximately $4 \times 5$ inches in its original form (see Figure 1).

See the extraordinary detail that you can have in this shot when we bring it to the edge of pixilation. There's the yellow light in the photographers dark room wagon and an Imperial camera on the ground and the cover sheet that goes around the photographer at the back of a wagon. A guy is holding a negative where you can actually see some of the detail on it... Then if you get back into the background, what's this? The Naval Observatory in Washington, D.C., the Capitol dome unfinished; the unfinished Washington Monument;

${ }^{44}$ Mitchell, "Visual Literacy," 16. 
a steamboat in one of the inlets; the towers of the Smithsonian Castle; all of that in that photograph.... And that to me is the magic. (P1, 14-15)

Participant 1's expertise was such that he could envision color in a blackand-white image and derive the name of a manufacturer from the shape of a partially obscured camera body. His ability to tell a story turns on the power of digital zoom technologies to find detail in the foreground, the midfield, and the background that could not be obtained from the relatively small original negative on a lightbox with a loupe, even if the 148-year-old negative could be handled in such a way (which it cannot). His research is impossible to undertake without data-rich digital surrogates.

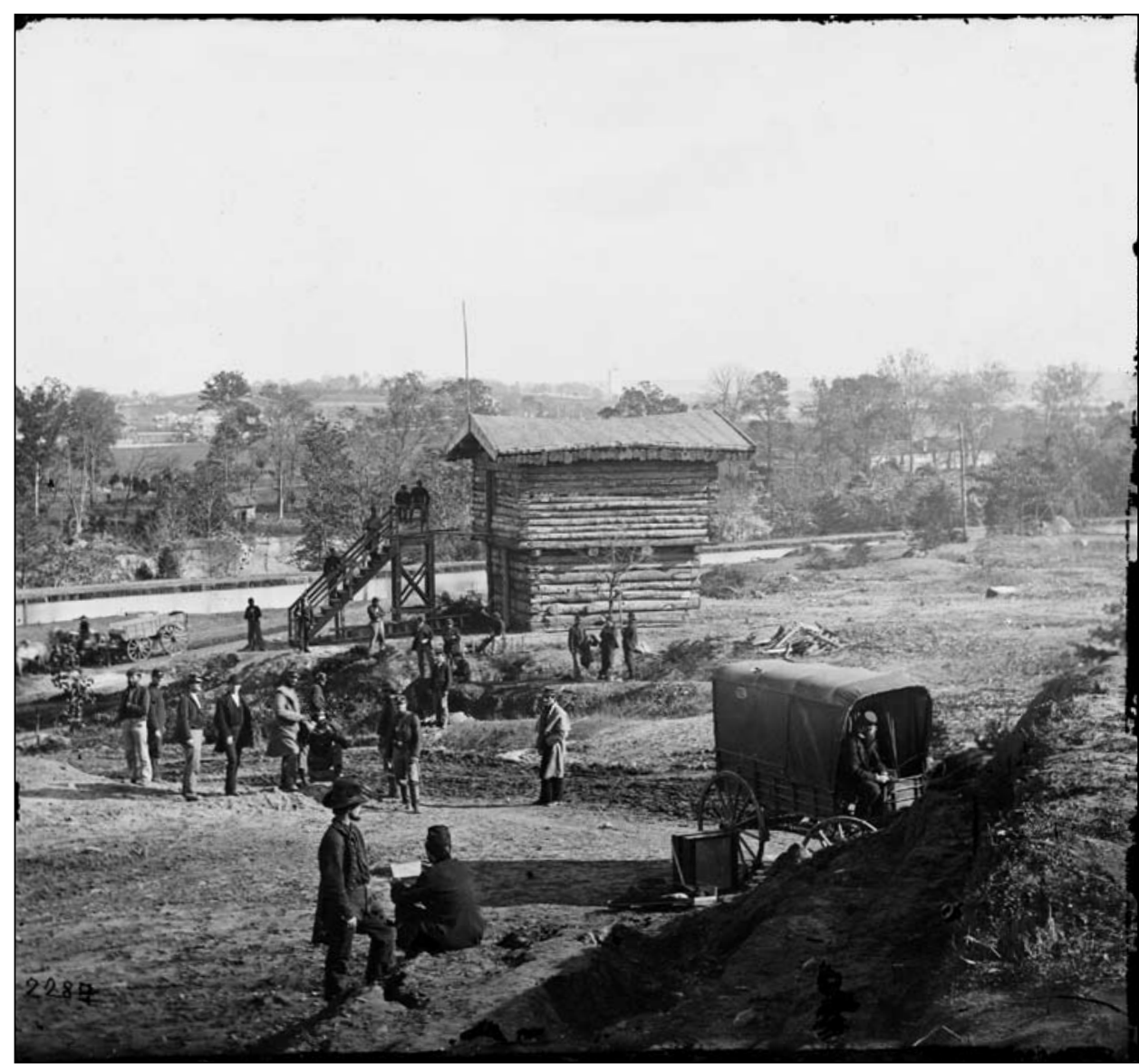

F I G U R E I. Arlington Heights, Virginia. Blockhouse near Aqueduct Bridge, 1861-65. Wet collodion glass stereograph negative, LC-B811-2282, Selected Civil War Photographs, Library of Congress Prints and Photographs Division. Digital file from original negative, available at http://hdl.loc.gov/loc.pnp/ cwpb.01439. 
M O D E S

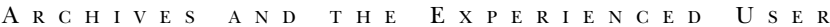

Participant 7 used a similar form of digital detective work to identify portraits of individual baseball players, which subscribers add to a database. "I'll use individual photos because that's what the user wants. I will use team photos if there's no other way to get a player's picture" $(\mathrm{P} 7,16)$. His work involved painstaking reading of individual photos for identity clues:

The thing that is most important to us is recognition of faces. It's almost like forensic science, being able to compare one face and one photo with another face and another photo and match them up. There's one fellow of ours who has this ability to magnify ears and be able to say, "That is not the same guy as that, because the two human ears are not alike." $(\mathrm{P} 7,4)$

The results of such painstaking looking, examining, comparing, and judging may be a more accurate description of the image. For the player depicted in Figure 2, Participant 7 summarized the satisfaction that derives from finding such errors:

Well it turns out that sometimes those last names etched on the photographs were wrong. For example, as we got more sophisticated and compared faces, we found out that last name we thought was Herb Pennock wasn't Pennock at all, it was [Weldon] Wyckoff, so in this second go around sometimes we're discovering those errors. $(\mathrm{P} 7,6)$

For some users, seeing digital images is a holistic undertaking that registers the visual power of the entire composition. For example, in Participant 2's work with a rare album of original photographic prints, the field of view encompassed the photograph as a whole object whose very existence speaks to its value:

You don't just look at the center of the frame, you look at the corners; you look at the edges. You see what's going on. You look for movement, and in $19^{\text {th }}$ century photography that's easy because the image is blurry. But with Central Asia photography, or any type of colonial photography, no image is innocent. You have to understand the power or hierarchy that is being played out in these images. $(\mathrm{P} 2,8)$

Participant 3 also valued the composition of an image, factoring in subtle details of light and shadow and the positioning of the main subject. After expressing little interest in zooming on the image for detail, he described the choice of digital surrogates for study in terms of the photograph's iconic value, its beauty, and how the photographer speaks through the picture:

First of all the child is looking directly into the camera and somehow he got that child to look into the camera.... The disappearing point here, the relationship between her size and the spinning machine is important. The narrowness of the work space; there's this feeling that she's trapped." (P 3, 26) 


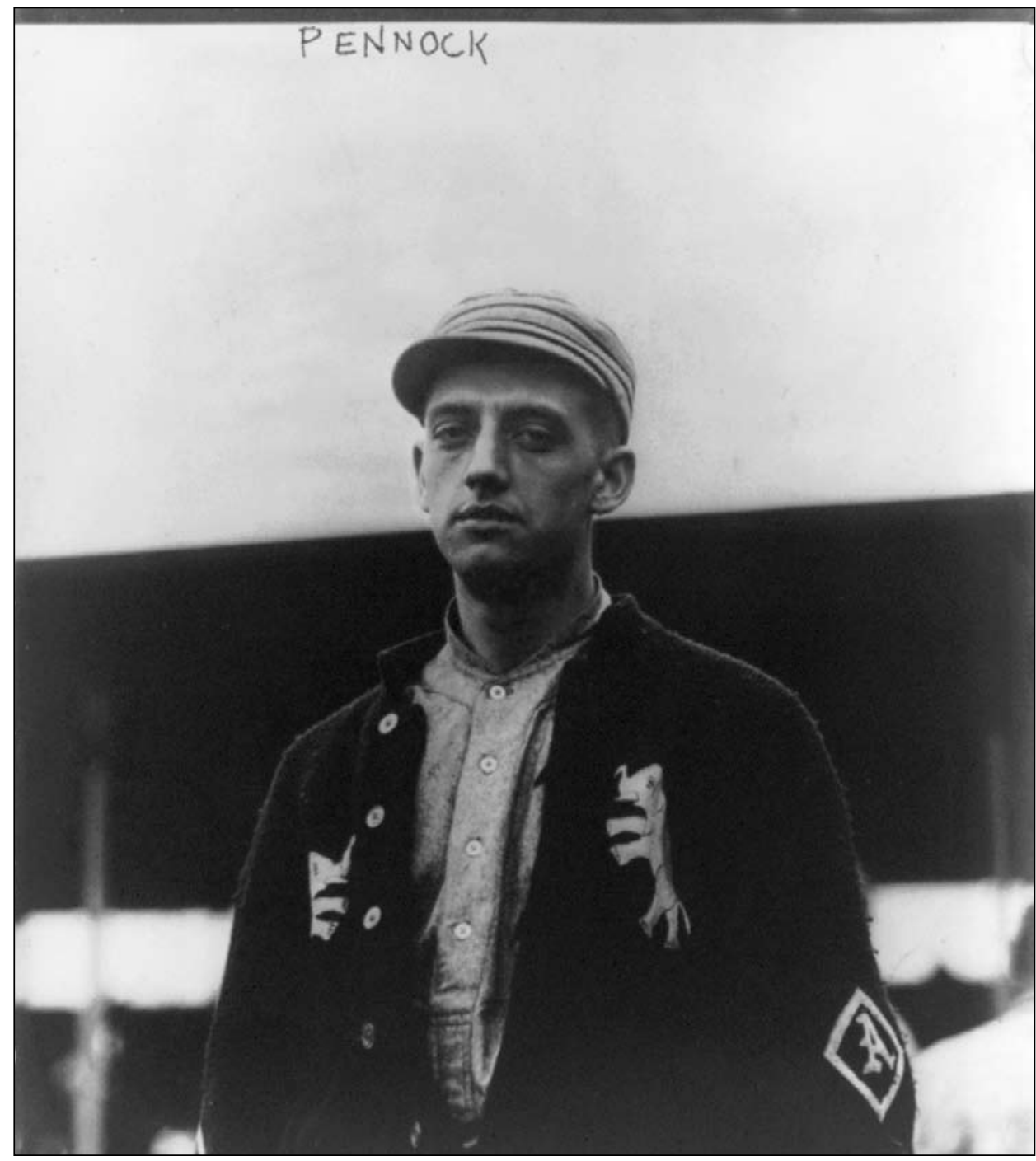

F I G U R E 2. Weldon Wyckoff, Philadelphia, 1913. Photographic print, George Grantham Bain Collection, Library of Congress Prints and Photographs Division. Title and date based on research by the Pictorial History Committee, Society for American Baseball Research, 2009. Digital file from black and white film copy negative, available at http://www.loc.gov/pictures/collection/ggbain/item/ 2001704361/.

The field of view extends well beyond the borders of a given image. Participant 2 was acutely aware of the importance of understanding the relationship between the visual content of an image and information beyond the border. Representation practice resides with the geospatial context of the photographer and scene and with the sociopolitical context within which the photograph was created and initially preserved (see Figure 3): 
M O D E

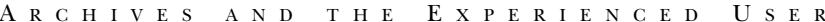
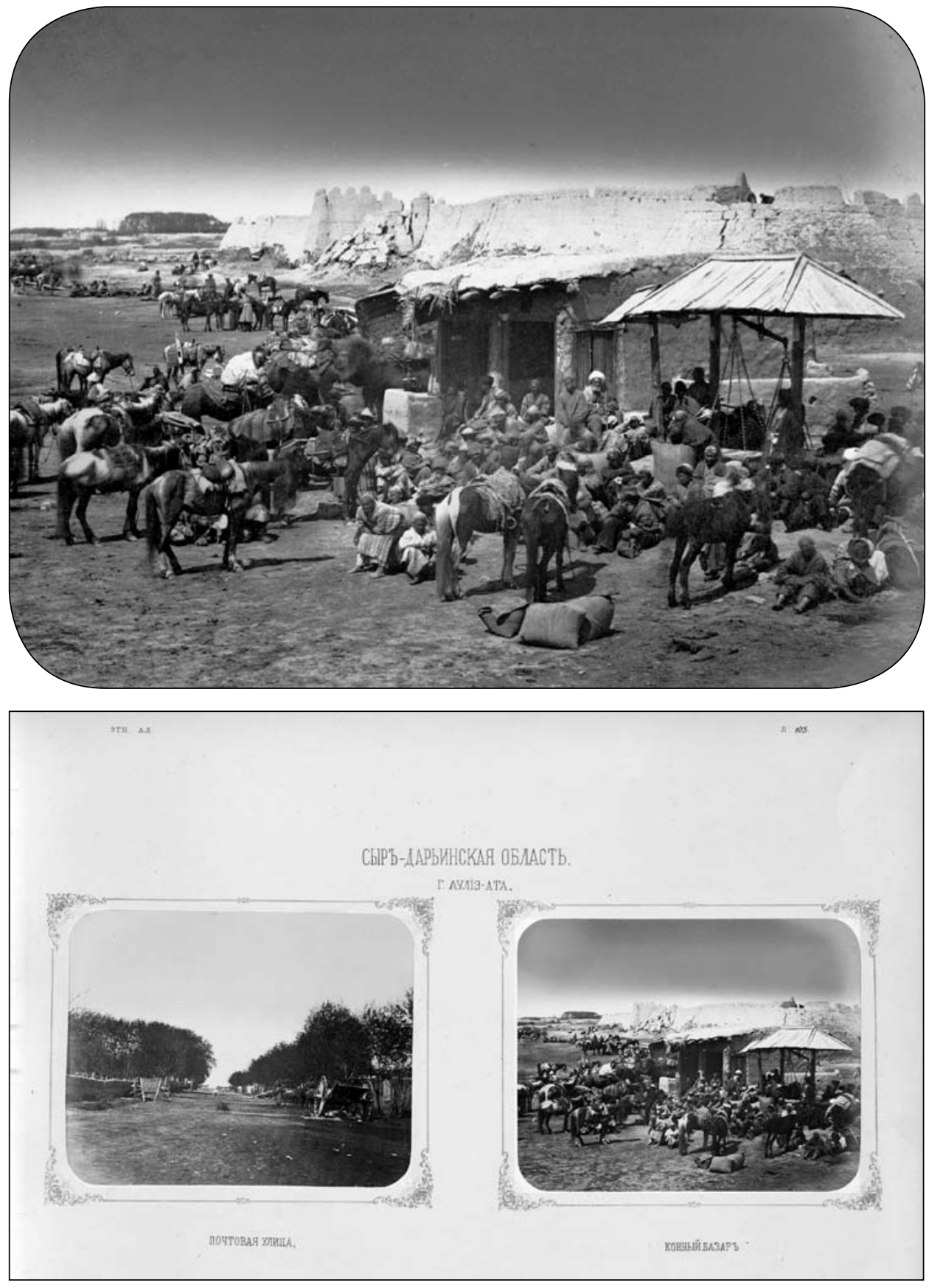

F I G R E 3 A-B. Horse Bazaarfrom Turkestan Album Ethnographic Part 2, volume 2, plate 103, image no. 25 (album page); image no. 323 (photograph), 1872. Albumen print and album page from album in 2 volumes, 6 pages and 164 leaves of plates, part 2, DK855.4 (Case Z), Library of Congress Prints and Photographs Division. Digital files of original photos, Part 2, ppmsca 09951, available at http://hdl.loc. gov/loc.pnp/ppmsca.09951. Digital files of original album pages, Part 2, vol. 2, ppmsca 09952, available at http://hdl.loc.gov/loc.pnp/ppmsca.09952. 
This image is of a horse bazaar. It's less about the digital transfer than all the content in the photograph. I'm selecting images that are conveying culturally particular aspects that the Russians seem to be honing in on [in assembling the album]. The Russians were very interested in keeping up their cavalry, so they might not just be conveying an ancient commercial practice of Central Asia, but also one that they're deeply invested in for their own purposes of controlling the land. And it has to do with horses, and the horse culture, and both cultures kind of coming together in the same encounter, the colonial encounter. (P2, 31)

The field of view encompasses the spaces between photos in a group as well:

I think I have a fairly intuitive approach to looking at the images for the content that's in the frame. And oftentimes that means looking at what's going on outside of the frame. I don't just look at the photographs individually but I look at them as an entire collection and the power they hold there. $(\mathrm{P} 2,7)$

Experienced users of pictorial archives see digital images not only as windows on the past that evoke an emotional response in the present, but also as pieces of a story whose ultimate value is in the telling. For each of the participants in the study, seeing images equated to seeing an end product, realized in part through individual effort and in part through the power of publishing in print or through the Internet. Participant 1 mentioned two working strategies for the selection of photos for a book on Civil War photographers:

The primary strategy would have been very unusual, previously unpublished, different photos, different, something that people haven't seen in other books. (P1, 22)

A little further on in the interview, Participant 1 mentioned a second strategy: illustration of the story:

And then the other thing is just finding images distinctive for historical context...some of these are just kind of normal shots to help illustrate the chapter about the bombing of Charleston. (P1, 23-24)

In both cases, Participant 1 used digital images as pictures not for their own sake for personal learning or narrow ends but rather in the context of a specific, tangible product. For all of the participants, if the image fit the purpose and the product, all that remained were technical decisions relating to publishing.

Emotional resonance of image

As a representation of a moment in time, an archival photograph has the capacity to carry its emotional aura into the digital realm. Participant 3 
M O D E S

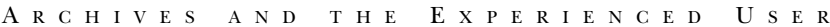

established a visceral, nearly personal relationship with both the photographer and the photographer's subject, though both are long since dead. This relationship survives the digital imaging process itself, as well as the display on a relatively low-quality computer screen under less than optimal viewing conditions (see Figure 4).

I think mainly it was the fact that you cannot look at this picture without being drawn right into this girl, who she was, and whatever happened to her? But in terms of the choice of this picture I think...ultimately it may simply be the fact that Hine had this gift for telling me this girl was important. This girl mattered to somebody...this girl was worth something in society. She wasn't just what he called "human junk." She was a real person. There's no sense of pity here. She looks strong; almost defiant. You want her to survive. You care about her. I think Hine was almost telling me: "Pick this one up." (P3, 30)

As his allusions shifted tense from past to present, Participant 3 described an image of a young girl, employed as a spinner in a cotton mill. The digital image reproduces one of nine photographs taken by Lewis Hine in and around Whitnel, North Carolina, in December 1908-but only this photograph carries sufficient emotional resonance and a clearly identifiable child.

The emotional connection between the original negative and the circumstances of its creation can be equally strong. Reproduction and the processes associated with delivering digital surrogacy carry as intense an emotional power as is often attributed to the original artifact. Upon learning that technicians would create a photographic print from a camera original, Participant 1 recalled:

My jaw dropped. You were going to pull that plate out and give me a contact print with the same actual artifact that was exposed to the sun that day on the Antietam battlefield? To me this is a visceral tie of an actual direct contact [with the battle]. (P1, 8)

Later in the same interview, Participant 1 expressed some of the same emotion when viewing a digital version online. "The digitizing project allows you to visit the Antietam battlefield in an incredibly intimate way" (P1, 55). In both cases, surrogacy transmitted directly the aura of the bloody battle itself, not simply the aura of a historic artifact (glass-plate negative or original photograph).

Participant 7 related that one of his most important contributions to a baseball history project was serving as an arbiter of accuracy within his community of baseball researchers by countering the emotional reaction that sometimes accompanies discovery of new connections between digital image and historical event: "It is part of my job as the middle guy to be a little bit dispassionate" $(\mathrm{P} 7,20)$. The emotional power of the digital image extends to 


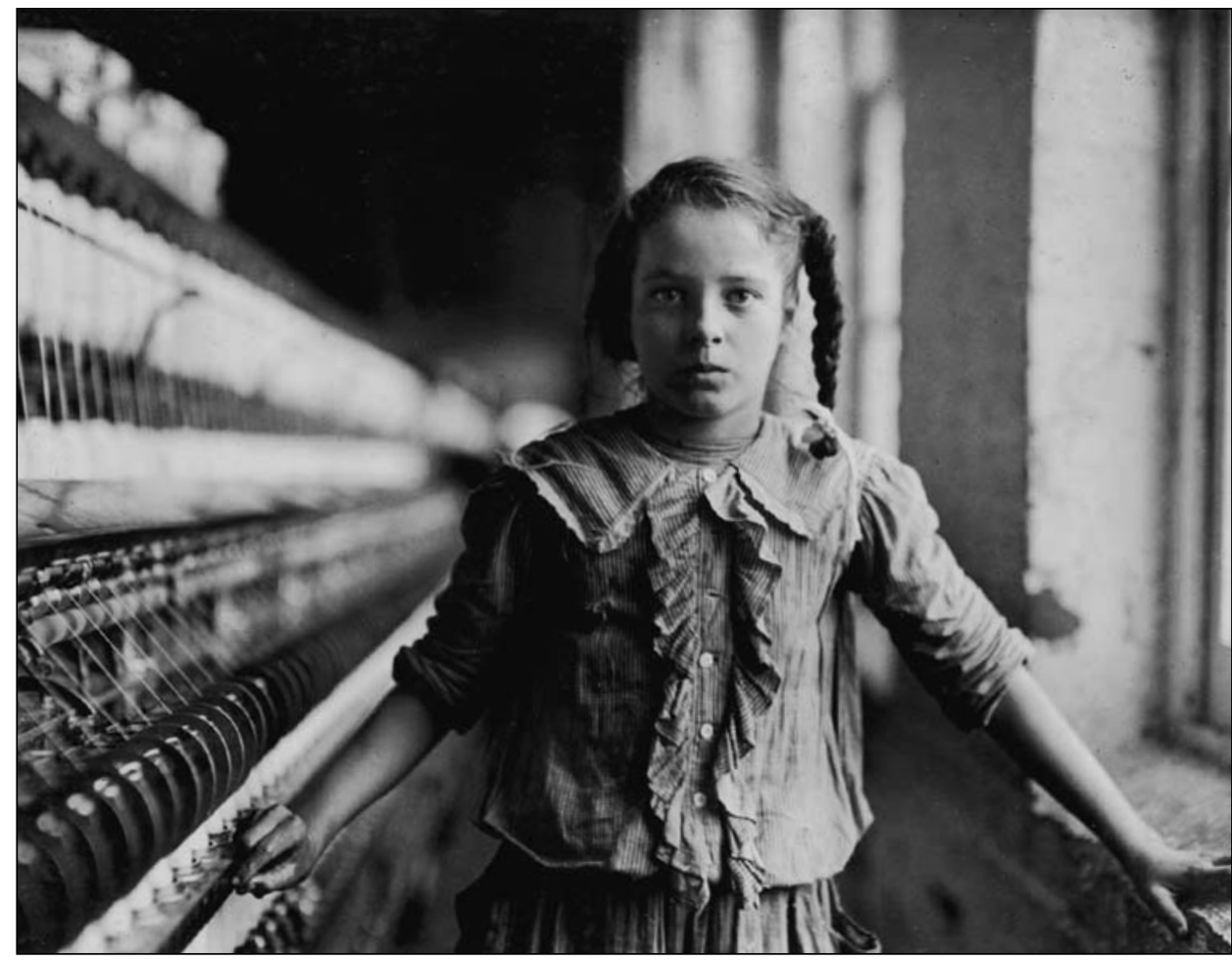

FI G U R 4. One of the spinners in Whitnel Cotton Mfg. Co. N.C., 1908. Lewis Wickes Hine, 1874-1940. Photographic print from the records of the National Child Labor Committee, Library of Congress Prints and Photographs Division. Color digital file from black and white original print, available at http://hdl. loc.gov/loc.pnp/nclc.01555.

the research process itself. Participant 7 frequently referred to the passion of his group of researchers, passion for baseball, certainly, and passion for finding images of the few hundred professional baseball players not previously identified. But passion sometimes clouds the judgment of enthusiasts, working against rigorous certainty about the truth of names or the quality of the images used to identify baseball players:

The passion-person who wants like anything to get the last 605 photos doesn't care a whit about the quality of the picture. He's looking for the face. He doesn't care if the picture is of the player when he was 92 years old in the church directory. It had nothing to do with his playing days or anything. I'm afraid that there's a point where emotion takes over. (P7, 19-20)

The emotional association of image to an obscure past extends beyond individual digital photographs to envelope an entire project. Participant 3 was 
M O D E S

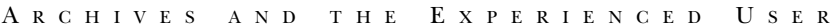

a natural storyteller. Here is his (abridged) recollection about how he first became involved with the Hine photos:

The origin of the project was very serendipitous, actually. I have a very good friend who finished writing a novel, ${ }^{45}$ and she said, "I really now need to know what really happened to this girl." I got really excited about doing detective work like that and I just said, "Sure, who knows what I'll find." And it took me eleven days to find her. Eventually I found the whole story of the girl. I thought it was the most emotional thing that had ever happened to me. I felt kind of like Jimmy Stewart in Vertigo following Kim Novak around and I thought, "Well what am I going to do about the rest of my life now that this project is over." $(\mathrm{P} 3,15)$

\section{Findings: Seeing Pictures}

Mitchell's distinction between image and picture compels us to consider the relationship that users have with original photographic prints and negatives, given the clear engagement that they have with digital surrogates. Experienced users make distinctions regarding the need to interact with original source materials; some privilege the original source, while others rely on the surrogate to satisfy most, if not all, of their information needs.

Privileging the original over the surrogate

Three of the seven participants had spent considerable time handling and working with the original source photographs that they used online for their projects. Participant 1 consulted prints of Civil War negatives early in the project and was also invited by Library of Congress staff to witness and assist with digital scanning of original camera negatives. As an intern at the Library of Congress, Participant 2 processed the Turkestan Photo Albums and prepared a finding aid and caption transcriptions with translations. Participant 5 processed photograph collections as a paraprofessional in a number of archival repositories prior to beginning her career as a consultant. All three of these participants were adamant about the value of handling original photographs as part of a research project. Their argument emphasized the passion that derives from intimate familiarity with the sources, rather than from the need to overcome the limitations of digital surrogates.

\footnotetext{
${ }^{45}$ Elizabeth Winthrop, Counting on Grace (New York: Yearling, 2006). In an afterword, Winthrop tells the story of finding the real girl behind her imaginary mill worker. Addie Card lived to be ninety-four and "never told her descendents about the day Lewis Hine took her picture. She never knew that her face ended up in a Reebok advertisement or on a postage stamp issued a hundred years after her birth or that Hine's original glass plate negative resides in the Library of Congress.... Addie lived the dark side of the American dream," 226-27.
} 
Participant 2 favored original photographs over their digital reproductions for purposes of study and interpretation, returning to the original albums for details and in appreciation of their aesthetic qualities:

I use my eyes with the original as my key data collector and then I make notes... I've done this for every single album. I think that sitting with the computer and looking through this I would miss a lot of this detail. It meant so much to be there up close $(\mathrm{P} 2,37)$.

Further probing of her simple statement "I always privilege the original" $(\mathrm{P} 2,13)$ yields evidence that the specific limitations of the digital product were of paramount concern. Participant 2 took issue with cropping decisions made during digitization that obscured the material properties of the original photos and their physical contextual clues:

With [images of individual photographs] you get the frame cut off; you're only looking at the photo. But the frame that is either gold or blue is cut out. I like the frame. I think it's pretty. I think it's a little something special that people might not think that it has color because these albums are really beautiful physically in their presentation. (P2, 13)

Other technical limitations of the digital surrogate include insufficient resolution for exploring details within the individual images, poor navigation and page-turning at the interface level, and inflexible tools for zooming, rotating, juxtaposing, and otherwise manipulating displayed images. These issues may be most relevant to the digitization of photograph albums, which present complex problems with the relationship of physical structure, intellectual integrity, and the representation of spatial hierarchy (volume, page, multiple images per item, arrangement of items, captions, other metadata, etc.) The issues that Participant 2 raised about internal structure and navigation could well apply to other complex information sources, particularly heterogeneous archives and manuscript collections that are not organized or bound by the conventions of publishing.

Privileging the surrogate over the source

Four participants had not consulted original photos and saw no need to do so for their particular projects. Participant 6's projects, by definition, were limited to exploring collections of already digitized photographic archives; her role as assembler and editor did not require consultation with original resources. She relied on a contractually defined division of labor between researchers, who recommend the choice and sequencing of images, and book production specialists, who consult original source photographs to determine if publication requires specialized reproductions. In a statement that demonstrates the 


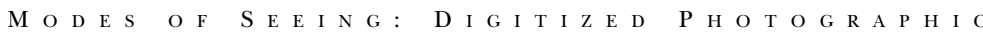

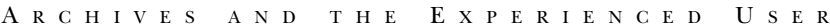

representational limitations of surrogacy in any form, Participant 6 noted that only the shape of the final product matters:

I never really trust the online file until I see a proof, a printed proof. Because I work in the print medium, the screen lies no matter what it is. It's just a total lie. And this [book] is a total lie too, but this is a lie I have to make perfect. We really worked on this to get these photos to look like this. They probably never looked so good when the photographer took them. (P6, 24)

The product developed by Participant 7 is an online database of digital images and metadata, whose only value is the verified content it contains. Verification, in this case, came not from the original source but rather from the evidential information transmitted by the surrogate's context and the information content detectible in the digital surrogate itself. Value that might be derived from the material properties uniquely embedded in the source photograph are, at best, of tertiary importance, after the visual evidence transmitted through the digital surrogate and the relevant contextual information written on the object or derived from the image itself. Even though Participant 7 was a leader in a vibrant community of researchers that also collect, trade, and sell original photographs, his perspective on archival photographs was decidedly nonmaterial.

Participant 4, a professional photo researcher, relied on third-party assistants to consult original items, passing on the costs of their efforts to clients. In his choice of photographs for a project, he typically privileged archival material that was fully available online or that was described well enough online that digital copies could be ordered from archives or libraries:

Most projects you can cover what you need to without making a research trip because so much of it is online or things are available elsewhere or you find another way to illustrate it. (P 4, 15)

Participant 3, creating a dynamic website about the descendants of child laborers, was thrilled by the immediate tangible rewards of online research in the comfort of his home. For him, the technical characteristics of the digitized photo (e.g., varying resolution, image cropping, reverse polarity) typically played a secondary role in the decision to investigate a particular image. Knowledge about digitization parameters or postscan enhancement processes was not an important consideration, so long as the visual content of the image and its overall archival integrity were intact: "I think as long as the photograph does its job to draw you into it I can overlook a chopped off corner or crack in it or a tear in it" $(\mathrm{P} 4,15)$.

Participant 3 disdained any cropping of the original image in an online presentation: "The fact that you can see the borders around it indicates that the whole photograph is there. It's very important for me to know the whole 
photograph is there. Because there are a lot of things in that photograph that might be very important" (P3, 39).

Participant 1, who delved into the details of Civil War-era photography, used the digital surrogate as a mental placeholder that allows him to move fluidly between a discussion of the properties of the original photographic print and its representation in digital form. In discussing the photograph reproduced in Figure 5, he made note of the differences in the depiction of color and tone between a digital reproduction of a historical print versus the original glassplate negative:

In this case the print is what's called a "Yellow Mount Anthony Card," whereas what we are seeing is a scan of the negative. Now this is strictly black and white because that's what you find on the negative. The print is sepia toned, that's because it was printed on albumenized paper, yielded a brown-tone print. $(\mathrm{P} 1,34)$

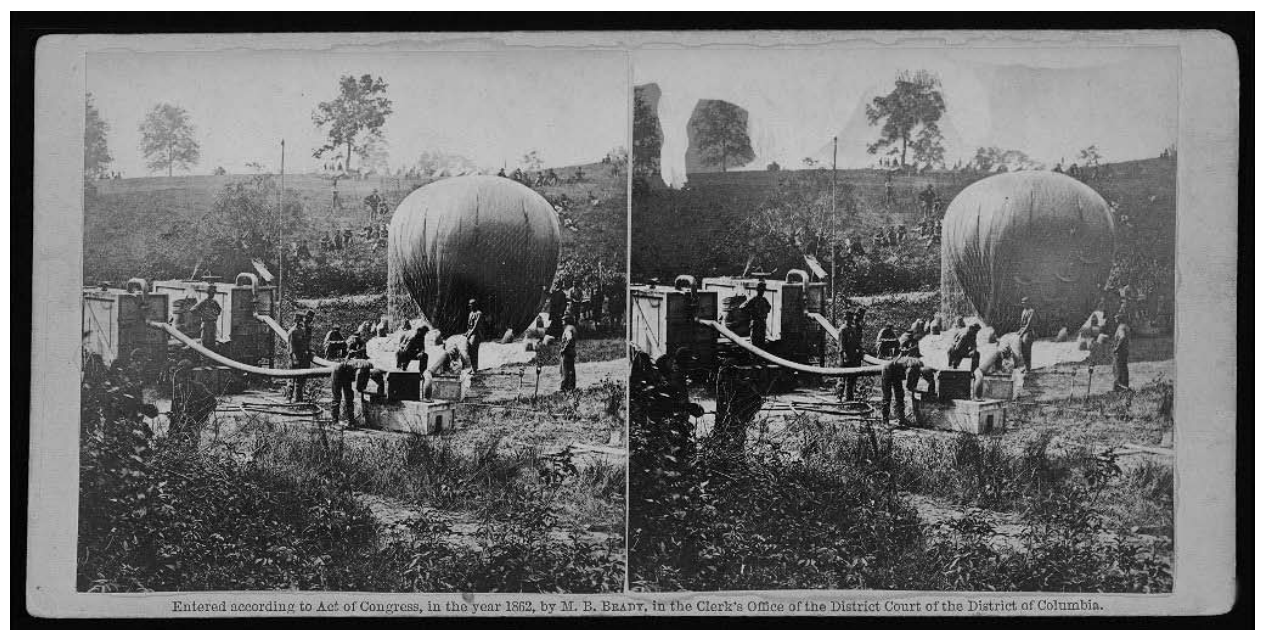

F I G U R E 5. Professor Lowe inflating balloon Intrepid to reconnoiter Battle of Fair Oaks, 1862. Stereograph from Brady's Album Gallery, 423, PR-065-806-3, from Civil War Stereographs, New-York Historical Society. Digital ID nhnycw/ad ad36003, available at http://memory.loc.gov/cgi-bin/query/D?cwnyhs:1:./ temp/ ammem_atxR.

Users who work exclusively in the digital environment face a dilemma in attempting to identify visual truth. If the surrogate has questionable features, such as blemishes or partial blurring, the recourse is sometimes the least-worst option of rejecting the item in favor of one that may have less emotional power but greater visual clarity. Participant 6 described her logic of settling on an acceptable digital surrogate, referring to the photograph reproduced in Figure 6. The photo depicts prison convicts performing for the depression-era FSA photographer, Jack Delano. 
M O D E

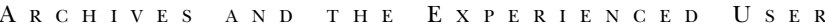

For me I guess I don't really know what the negative looks like so it's a real quandary; how do I know for instance whether the negative, the print, or the digital scan is bad.... I tend to go just sort of with what I see and so I say to myself: “Gee, that doesn't look like a very sharp image." I often do decide on a sharper image over one that's less sharp. If this is the only picture that I really thought was interesting, I would go into the file and I look at the file print to see if the print is clear and if it is I ask for a new scan from the camera negative. $(\mathrm{P} 6,27)$

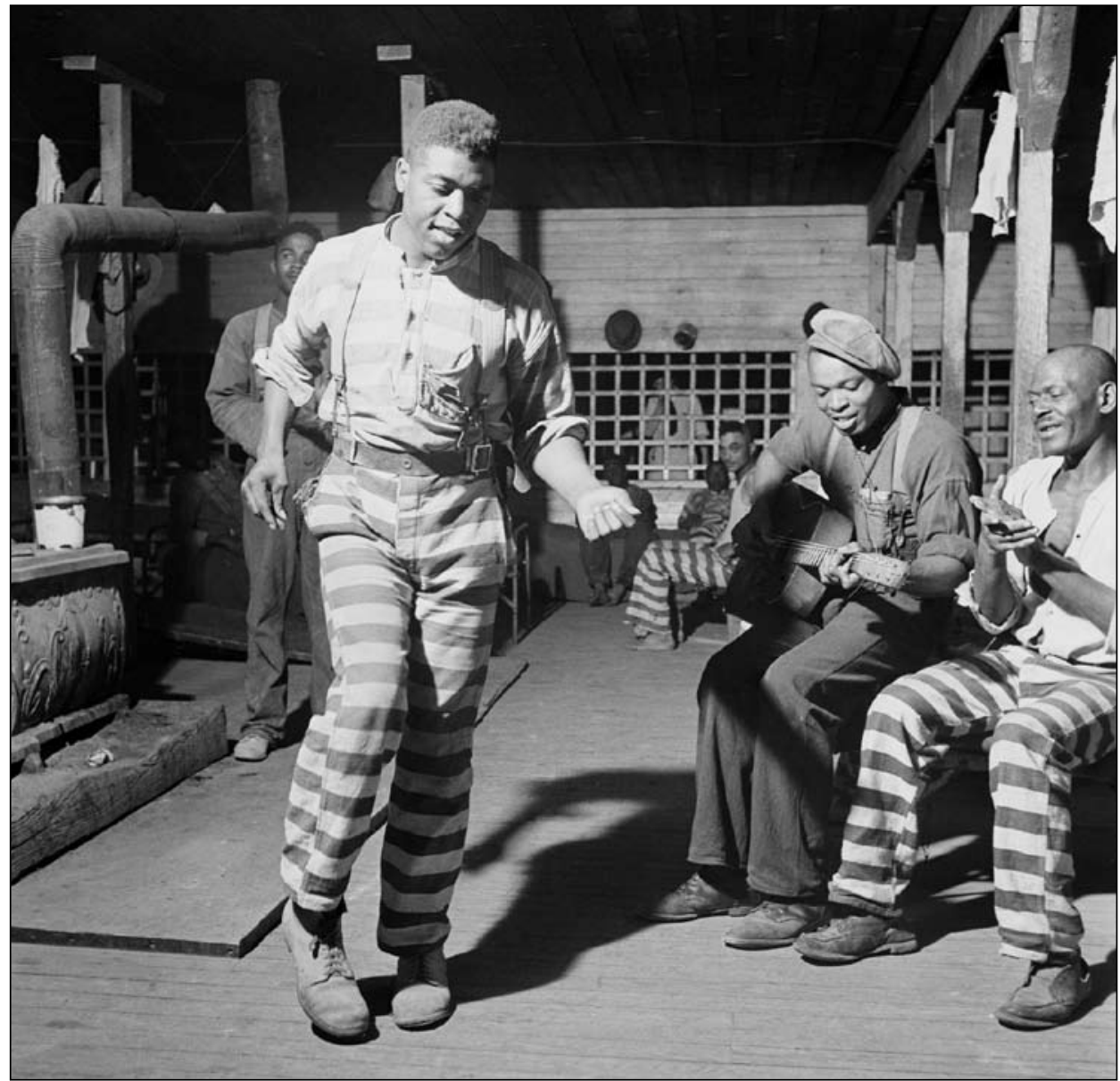

F I G U R E 6. In the convict camp in Greene County, Georgia, 1941. Jack Delano, 1914-1997, photographer. Nitrate negative, Farm Security Administration-Office of War Information Photograph Collection, Library of Congress Prints and Photographs Division. Digital file from original negative, available at http://hdl.loc.gov/loc.pnp/fsa.8c29075. 
Participant 5, writing a biography of photographer Russell Lee, had a very strong affinity for the material artifact and insisted on using and handling original photographs and related archival materials. Neither the original photograph nor its digital surrogate was sufficient to meet her needs:

Sometimes the digital is fine to use for research purposes. Sometimes you have to actually have the physical thing in front of you. Sometimes it's a fine surrogate and sometimes it's not. In a lot of ways the digital is far superior for mining information, just because of the way that it is arranged. And that's what I find is the ease of access to it; but sometimes the quality isn't high enough and I can't see and I have to actually go and look at a file print. (P5, 9)

Speaking from her perspective as someone who had worked in an archives, she was skeptical of research that purports to be done only online: "What concerns me is people who have never set foot in the reading room and they've written an entire book about something as an expert" (P5, 15). Because Participant 5's approach involved iterative consultation of full-frame digitized negative and file prints, her expectations for the digital version were perhaps a bit lower than would be the case if she did not feel compelled to view original file prints:

Well my view is that the scanned collection should be as close to a neutral presentation of the collection as it exists when digitized. This image that we are viewing is of a print that is sepia because it has aged. I know the original is gone. $(\mathrm{P} 5,34)$

And yet, given the preservation of the physical file prints, Participant 5 was comfortable with a digitization project that draws primarily from the negatives in full-frame view:

Digitize the negatives; and if you want the tonal values of the file print go to the reading room. To me the digital versions are tools. That's all this is for me is a tool. And it doesn't tell the whole story. It tells a different story. (P5, 35)

\section{Seeing Archives}

Although only two of the participants in the study had experience or training as archivists, all participants saw collections of digitized archival photographs as possessing archival properties. As boundary objects, digitized photographs exist in an environment where the terms of their preservation and management endow them with levels of trust that may exceed trust in the properties of the original photographs themselves, which largely remain unseen and untouchable in cold storage. 
M O D E S

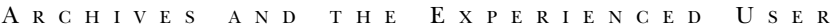

Surrogates as archive

Participant 4, though not a trained archivist, had a sophisticated understanding that archives derive much of their value through secondary use-information and evidence that serve purposes never intended by the creators: "One of the things that I think is really exciting about historical photographs is the unintended historical record as well as the intended one" (P4, 33). He found inspiration in the gaps in the archival record of depression-era photographers included in the Farm Security Administration collection:

Some people criticize the FSA for not creating better documentation. There is plenty of documentation and the rest is up to us. If FSA photographers had taken scrupulous notes and we knew exactly who these people were, and they had done very methodological ethnographic field work along with this, there's no project here and just no excitement. The archival record is like a joke, it's about building the tension and then releasing it. Without the tension being built first there's no excitement in tracking it down. (P 4, 37)

As with the blues singers that he pursued for a book, Participant 4 saw accumulated archival value through the difficulties that archives endure through a record's life cycle. "A lot of stuff has to have a risky life before it gets archived. Life has to be life first and often stuff has to go through a period of worthlessness before it becomes worth saving" $(\mathrm{P} 4,37)$.

The example that best illustrates Participant 4's point about "unintended history" is a photo sequence, partly depicted in Figure 7, of a street scene in Mississippi that yields, on close inspection, the image of a street musician drawing a crowd that dissipates over time:

I picked up on this guy and he's playing a guitar, Spanish style because it's a metal guitar and he's got the hat. Playing on the street for downtown crowds for change is a really core thing for blues musicians. I've never seen an actual photograph or any visual representation of that situation and here is one. All the more remarkable because it was created by Marion Post Wolcott, who was just photographing the downtown of a cotton town. Ultimately that's a very cool factor of the FSA; they were good photographers who shot things in the right way. $(\mathrm{P} 4,40)$

Figure 7 shows part of the sequence. The street musician is not visible until the crowd parts, is not named in the caption, and so was not recorded in Wolcott's field notes. This story illustrates the importance of the immediate associational context of archival arrangement in determining the value of individual items. The archival context is clearly discernable in the digital surrogates. 

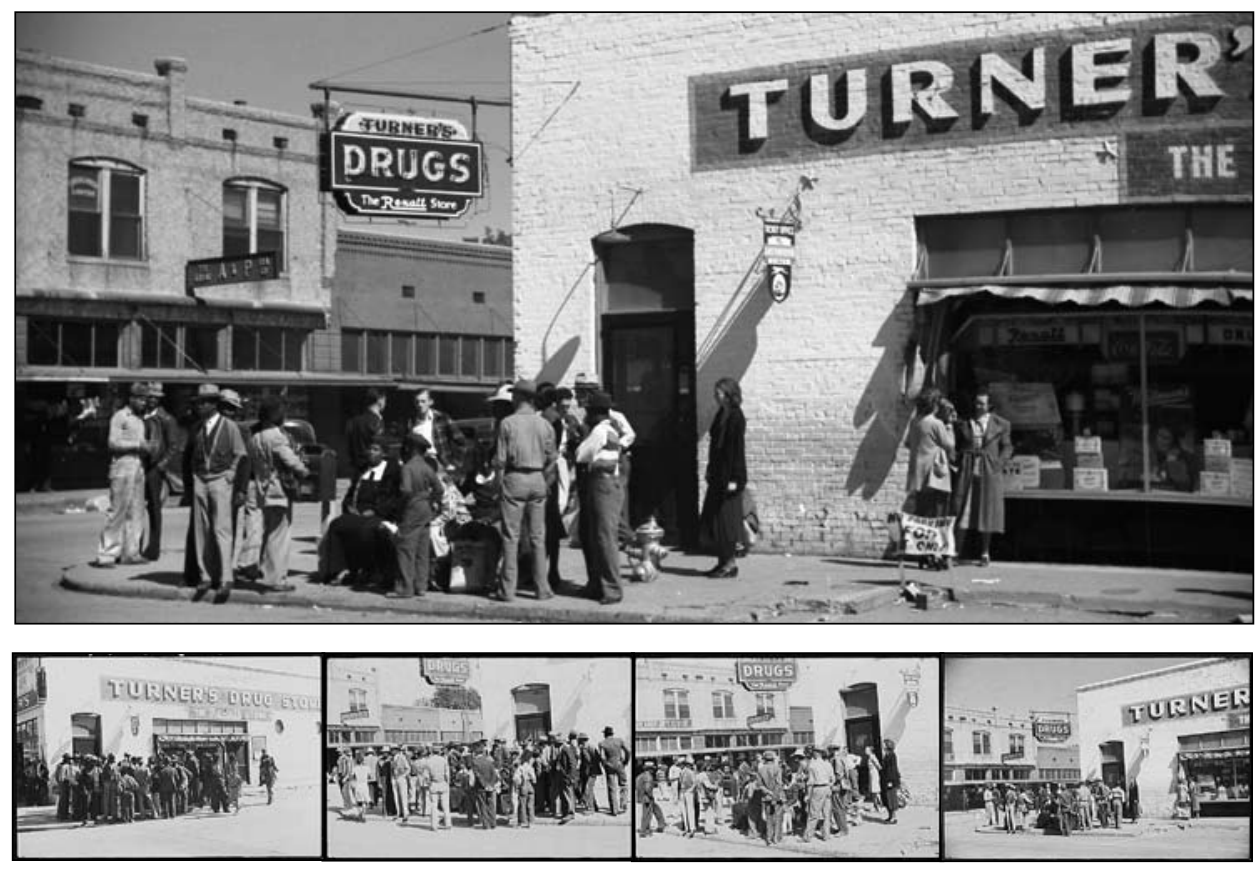

F I G U R 7. Main Street on Saturday afternoon, Belzoni, Mississippi, 1939. Marion Post Wolcott, 19101990, photographer. Black and white nitrate negative, $35 \mathrm{~mm}$, Farm Security Administration - Office of War Information Photograph Collection, Library of Congress Prints and Photographs Division LC-USF33030592-M1. Digital file from original negative, available at http://hdl.loc.gov/loc.pnp/fsa.8a41181.

Participant 2 considered the individual images as parts of a whole that emerges through reconstruction. Her efforts to plot the creation of individual photographs were explicitly geospatial and temporal in character:

The sequencing of images in the album shows their movement from say the city in Southern Kazakhstan, and then they move to the next city and they take photographs, and then move to the next city, and it's literally spatial movement along an itinerary that was military lined. $(\mathrm{P} 2,33)$

Her contextualization of the archival record over space and time turns on the type of detective work that is a common feature of contemporary rephotography, which is the practice photographing the same scene at two points in time, popularly referred to as "then and now" photography. Participant 2 asserted that rephotography was a factor in the expression of colonial power by the Russian occupiers. In the interview, Participant 2 showed two digital images of photographs taken roughly eight or nine years apart (ca. 1864 to 1872) and published in two separate photographic albums:

All these buildings right here which are half completed have been white washed and this is a sign of Russian military occupation so they've turned into barracks and administrative zones. (P2, 35) 


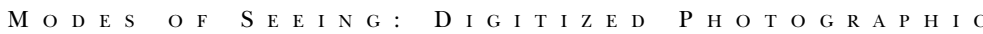

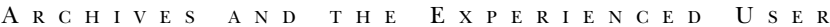

In this example, Participant 2 used contemporary Russian photography of the same scene over time to reinforce the image of their control of the area. "No, I think the Russians had an agenda to show the difference, to go "Veni, Vidi, Vici'.... These two photos were both taken by Russian military officers" (P2, 35).

Digital surrogates in an archival context

Participant 1 described the ways in which he found new connections between and among photographs previously considered separately as unrelated. He constructed a visual and verbal narrative from apparently discrete visual elements by reconstructing the original order of the photographic record as it was created. Participant 1, who was not a trained archivist and expressed little interest in or knowledge of archival practices, displayed a nuanced view of archival photographs as traces of prior activity, in the way that Jeffrey Mifflin describes, ${ }^{46}$ in which the activity and not the mediated image-making is of greatest interest. Participant 1 relayed a story concerning a sequence of images from 1863 that portrays a scene across the Rappahannock River near Fredericksburg, Virginia:

All of these photos have been published elsewhere but I'm the first to put them altogether in one sequence showing actually the evolution of the battle from the front: basically a clear horizon; then smoke all along the front; the second battle of Fredericksburg; and then the whole city basically being obscured by smoke; and finally these two guys are watching the battle [from a tree top]. (P1, 23-24)

Discovery of new evidence to support an emerging story is a classic example of how evidential and informational values in archives converge to reveal a previously hidden truth. In this way, Participant 1 enacted thought processes similar to those academic historians use to assemble new knowledge from a combination of the information in archival records and the spaces between them.

Participant 5's work on FSA photographer Russell Lee led her to contextualize the photographer's output through reference to the surviving archival record of his work and that of his FSA associates:

And then after I got through reading through all the correspondence I thought, "I can reconstruct exactly where he was every single month that he worked for the FSA." From the captions, this is what he was photographing, from the correspondence, this is what he was writing, and this is where he was. In putting the three of them together I was able to construct his working methods. (P5, 20)

\footnotetext{
${ }^{46}$ Jeffrey Mifflin, "Visual Archives in Perspective: Enlarging on Historical Medical Photographs," American Archivist 70 (Winter 2007): 34.
} 
Participant 5's archival research did not stop with absorbing archival evidence, but extended to mapping the photographer's field work:

So I got a 1930s atlas and I highlighted every place that he went. This is a map of Iowa. He went from there, there, there, there, then he went back to here then he went back to Illinois. I don't think you could get more contextualization than what I've done. (P5, 21)

Participant 3 applied well-proven and sophisticated methods of genealogical research to confirm the identities of children in Lewis Hine's photographs and then track down their descendants to report his findings:

The first child that I identified I found in the death records and then I got an obituary and a photograph of another girl, unidentified by Hine. In Gastonia, NC, I found a nephew, and the girl Hine identified never got married, so I was able to find her death records pretty quickly. $(\mathrm{P} 3,16)$

Participant 4 also searched for the people depicted in digitized photographs that interested him. Referring to a child depicted in a classic depressionera photograph by Dorothea Lange (see Figure 8), Participant 4 remarked:

Yeah I found this mandolin player, this kid, he's now in his 70s, and I tracked him down. I asked him if he remembered meeting Dorothea Lange and being photographed by her and he said: "Well we had our picture taken in tents a lot back then." At the time, the FSA used Lange's photographs to tell a story of depression era heroism and the common man and all that and his take on it was: "We had our pictures taken in tents a lot back then." $(\mathrm{P} 4,36)$

From the perspective of experienced users, the archival nature of original photographic records transfers to digital surrogates with little or no loss of value. Participant 3 referred to his choice of people to investigate in part because of readily available archival records in digital form:

North Carolina and South Carolina and Maine have particularly good digital files on the Internet. It so happens that a great number of Hine photographs were taken in those three states as well, which is lucky. I tend to not favor Maryland, because they have almost nothing available. (P3, 22)

Participant 4 adjusted his research strategy to maximize the use of online resources: "I'm happy with what's online and if it's not online I just try to work around it." (P4, 15)

Trust in digital archives

The trust that experienced users have in the digitized photographs that they use is based upon a complex mix of respect for the Library of Congress as 
M O D E S O F

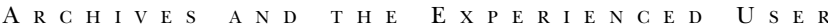

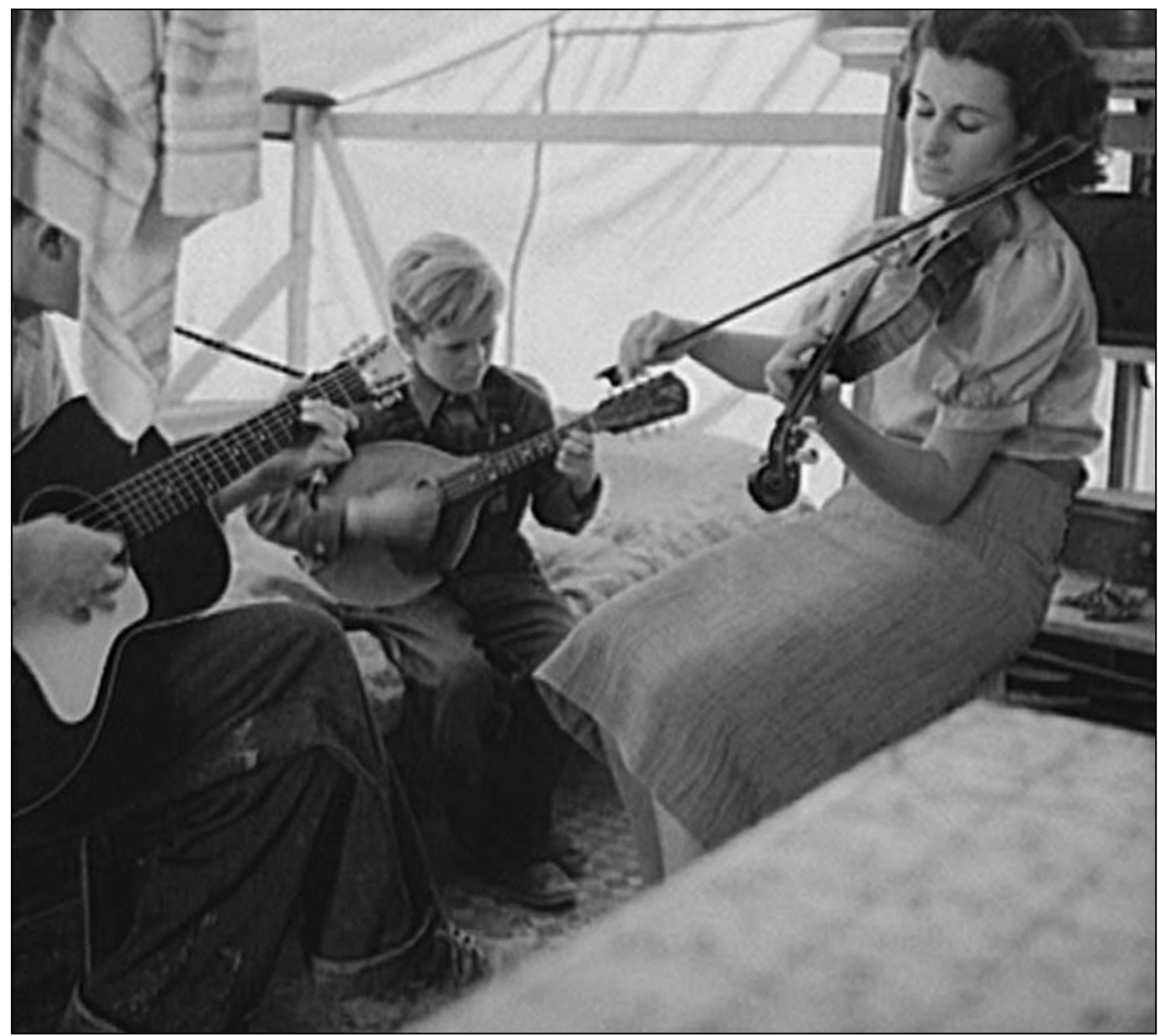

F I G U R E 8. Migrant Family from Arkansas playing hill-billy songs, Calipatria, California, 1939. Dorothea Lange, 1895-1965, photographer. Black and white nitrate negative, Farm Security Administration-Office of War Information Photograph Collection, Library of Congress Prints and Photographs Division. Digital file from intermediary roll film, available at http://hdl.loc.gov/loc.pnp/fsa.8b33352.

an effective agent of cultural heritage preservation and accumulated evidence that its digitization processes are reliable and trustworthy. Participant 3 placed significant trust in the Library of Congress as an organization that delivers trustworthy digital information, and he therefore did not much question the quality and trustworthiness of individual digitized photographs. He based his trust at the organizational level on his consistently positive experience in obtaining relevant, useful, and technically appropriate surrogates delivered through the tools of the Library of Congress's digitization program (P3, 28). In the absence of failure, disappointment, inadequacy, or other violations of good faith, trust ascends to the organizational level and, as a consequence, pervades the resources delivered digitally. 
Participant 1's trust in the archival nature of the individual digitized photographs derived from the comprehensiveness and completeness of the digital collection:

I mean they put some horrible stuff up online. I mean it could be cracked into seven different pieces (and they did break them, a handful of them over the last thirty years) and every time they broke one they put each individual shard of glass in its own separate envelope and they reassembled that thing like a puzzle on the flatbed scanner. So I totally trust that they're showing me everything, 100 percent of what they got. $(\mathrm{P} 1,45)$

Participant 1's confidence derived less from a technical knowledge of digitization processes, or even from assurances provided by the Library of Congress itself, but rather from his detailed and painstaking comparison of the numbering system in nineteenth-century photograph sales catalogs produced by Civil War photographers to market their products with the numbering system applied to the digital surrogates delivered through American Memory. Participant 1 related a long and detailed story about his discovery that the Gardner photo sales catalog from the 1880s actually lists Gardner and Anthony images in a meaningful sequence. The importance of this discovery for Participant 1 was not simply in tracking the creation of the original negatives but in cross referencing items from the original catalog into the numbering system that the Library of Congress retained for its images $(\mathrm{P} 1,55)$.

Participant 4 found great value in the power of the numbering sequences that the Farm Security Administration assigned to the negatives after receiving them from photographers in the field and developing them in Washington, D.C., laboratories. This important contextual metadata is the foundation of an online context-oriented browsing system for the FSA/OWI collection. ${ }^{47}$ According to Participant 4,

It's not an arbitrary assignment of call numbers that you're calling up here. Sometimes [the real value] is not a matter of digitizing, it's a matter of the assigned frame numbers. This is huge. Once you tap into this online browsing system, you get the social context of what's going on all around them and you get information of how the photographer traveled. Sometimes it's implicit and it needs to be checked against other things, because the sequence isn't perfect. $(\mathrm{P} 4,27)$

Figure 9 is the sequence of digital images to which Participant 4 referred. The image in the center of the strip is well known and published in depressionera anthologies. The surrounding images provide the social context of the scene, which the archival context of the numbering system validates, providing

\footnotetext{
${ }^{47}$ Carl Fleischhauer and Beverly Brannan, Documenting America, 1935-1943 (Berkeley: University of California Press, 1988), 338.
} 
M O D E S O F

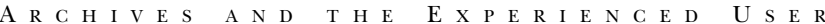
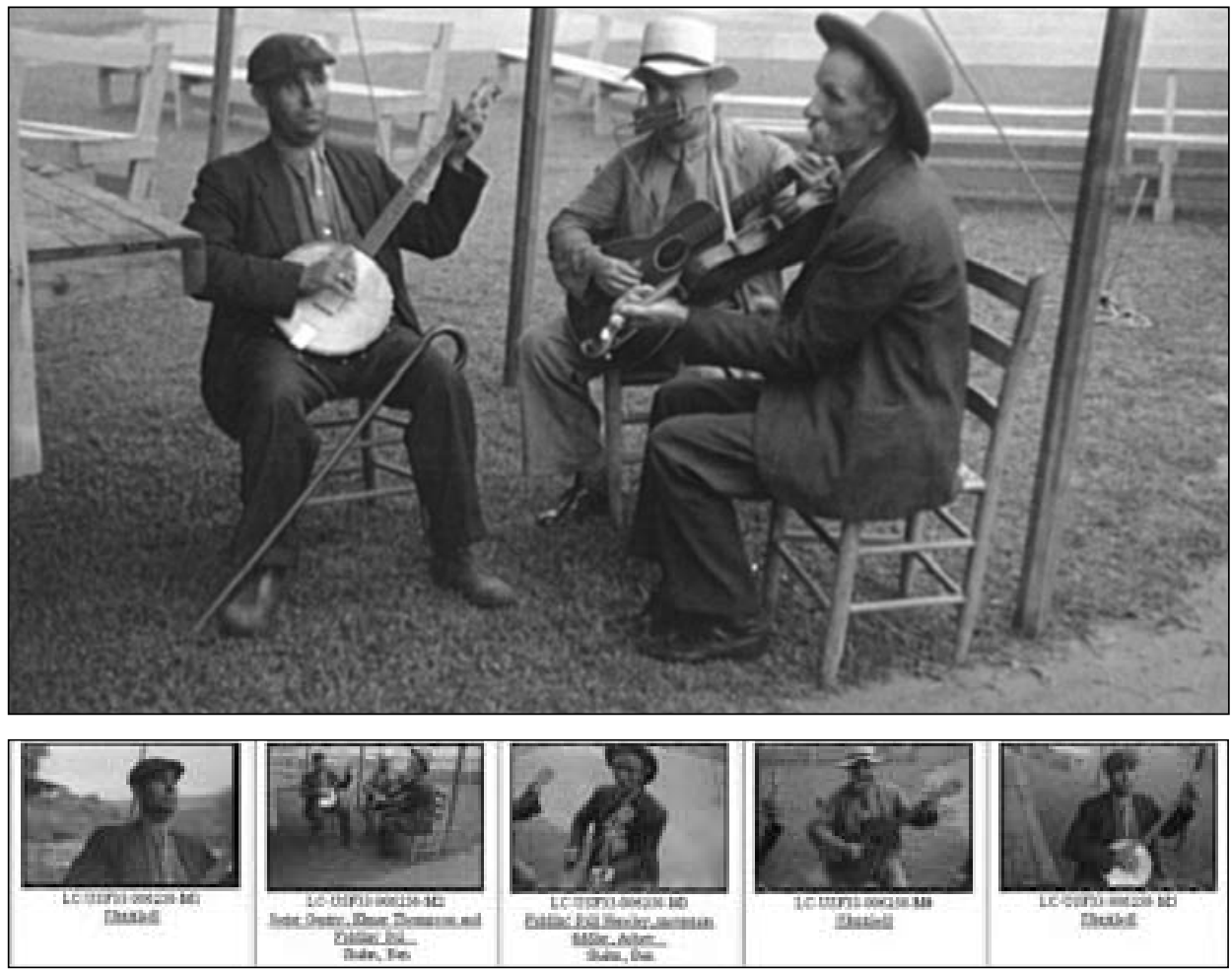

F I G U R E 9 A - E. Jeeter Gentry, Elmer Thompson and Fiddlin' Bill Hensley, Asheville, NC, 1937. Ben Shahn, 1898-1969, photographer. Black and white $35 \mathrm{~mm}$ nitrate negatives, Farm Security Administration-Office of War Information Photograph Collection, Library of Congress Prints and Photographs Division. Digital file from intermediary roll film, available at http://hdl.loc.gov/loc.pnp/fsa.8a17159.

a context-sensitive access not provided by caption-specific metadata. This sequence of thumbnail images represents the full power of the photographic archive. The archival nature is preserved and transmitted through the tools for displaying contextually related items.

Derived in part from the preservation mission of the Library of Congress, Participant 4's trust in the library's digitization standards and best practices freed him to focus on visual content and the context of original image production:

These scans are pretty good. A lot of this is just that the Library has excellent standards and I trust them; and if it were important to me I could know about what the particulars are, but it doesn't matter to me in this case and it doesn't matter to me in most cases.... But the truth is that the Library of Congress does everything exquisitely well and they do it far better than I would or I would know to ask, so I just trust it. (P4, 28) 


\section{Discussion and Implications for Theory and Practice}

Two theories not widely explored in the archival literature ground the research reported here. Mitchell's particular take on representation, derived from his mastery of literary critical theory, locates the building of large digital collections through digitization as communication between digitizer and viewer. Bolter and Grusin, informed by the constant churning of new representational media, provide a perspective that allows for the transfer of materiality from analog photographs to digital surrogates. Both theories recognize the loss of tangible information through representation and remediation; yet such loss may not necessarily equate to diminished value or weakening of the emotional aura of the original source-especially in the case of photographs that are grounded in particularly resonant historical events such as the Civil War, the Great Depression, or the colonization of Central Asia. Even in the popular case of American baseball, the joy of discovering a previously unrecognized player closes the gap between analog and digital.

People who are deeply experienced with the product-based use of digitized photographic archives are, this study suggests, passionate about the value that digitization of photographic archives adds to the experience of discovering new facts hidden in images, telling new stories about the past, and reconstructing a landscape of meaning that exists beyond the border of individual pictures. The seven participants in the study embrace the power of digital surrogacy to convey meaning on multiple levels. As images, the digitized photographic archives from the Library of Congress rarely fail to convey the visual content required to fulfill the purposes expected of them. In the majority of cases, the power of the visual image, represented as a digital bitmap and mediated through sometimes marginal computer screen technologies, transcends the limitations of the original media. If the composition is right, experienced users find inspiration and emotional resonance in digital representations of underexposed negatives, high-contrast preservation film, and broken, brittle, or faded prints.

Each of the participants in the study brings to the use of digitized photographic archives a particular vision regarding the scope, structure, and composition of a final product, even if the forms of the products are as diverse as a static website, a university press published book, or a Web-accessible database. Such purpose- or goal-driven inquiry tends to focus attention on the visual and material properties of the surrogates already identified for possible use, rather than on the strengths or limitations of the search and retrieval system itself. None of the participants in the study judge the value of the digital archive in terms of the capabilities of the delivery system. Research that focuses primarily on system capabilities, including interface design and search/retrieval tools, may miss the opportunity to understand end-user behavior with digital content itself. This study opens the door to a deeper investigation of the quality of 


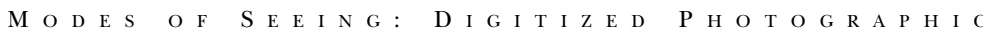

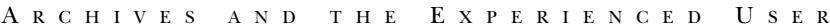

digitized photographic archives. Such an investigation must be carried out through a comparison of a variety of digitization processes and delivery systems.

For experienced users who are motivated by passion for the discovery process itself, time and effort are the currency of success. Without exception, each of these participants is willing to make a significant investment in a personal information management system that is capable of overcoming limitations in the labeling or numbering of individual items ${ }^{48}$ Experienced users are enthusiastically capable of tapping the navigational power of original numbering or cataloging schemes imposed on the original photographs by the agencies for whom the photographers worked, or by the publishers that established meaningful order well after the original events were recorded. Few found any value in the subject catalog terms assigned by librarians. It is possible that expertise and experience, combined with a deep engagement with producing a tangible product, obviates the value of subject classification. Future studies of the actual use of digitized photographs should explore the role played by subject classification of individual items in augmenting the user experience.

As a qualitative exploration of user perspectives on the digitized photographic archive, this research lays the groundwork for a quantitatively grounded study of end-user behavior. It suggests that there is much to be learned about the actual use of digitized photographs by people with a variety of product orientations. The field of view that experienced users bring to their work (detail, full frame, beyond the frame) drives their expectations for the technical characteristics of the digital surrogate. Not every user expects or will demand ultrahigh resolution, but those who do will be satisfied only with full information capture. Not every user expects or demands a browsing or navigation system that represents completely the relationships among discrete photographic objects, but those who do will find new meaning in context-sensitive search and discovery. The distribution of user expectations for detail, data, and use-tools in the general population of users can only be determined from large-scale user studies. Research that investigates the actual use of archival photographs in products that are distributed in print and online will effectively measure the impact of archives beyond research and learning that happens in the archives itself.

By design, this research project engaged experienced users of digitized photographs, each of whom pursued his or her work in the context of a specific project. Interviews that focus on the intersection of product and process may generate greater insight into the uses of archival photographs than do those that focus on the occupational status or organizational affiliation of the users.

\footnotetext{
${ }^{48}$ For evidence of the same phenomenon of information management practices among genealogists, see Elizabeth Yakel and Deborah A. Torres, "Genealogists as a 'Community of Records'," American Archivist 70 (Spring/Summer 2007): 102-5.
} 
In the environment of expert or experienced use of digitized archives, academically oriented researchers are no more likely to make sophisticated and high-impact use of digitized photographs than are researchers whose avocation leads them to adopt advanced genealogical research techniques or contract researchers who use ethnographic inquiry as a method for assembling a story line. This research demonstrates that the purpose or product of a researcher's work determines the fit of the sources to a far greater extent than do the technical characteristics of the digital surrogates themselves. For digitization practice, this research suggests the need for far greater flexibility in specifying digitization procedures than is currently the case. Efforts to advance digitization best practices in archives should look well beyond technical specifications to understand the rich variety of expectations that experienced users place on digital surrogates.

As presented in the literature, archival theory often reads to even the most experienced and capable archivists as excessively abstract. Archivists may sometimes find it difficult to grasp the relevance of archival theory to the management of archival programs or to detect the motivations of those proposing new ideas. Perhaps some of this disconnect between theory and practice originates in the seemingly mysterious nature of theory development itself. Anne Gilliland and Sue McKemmish focus on this issue, writing that "although the archival literature has been replete for many decades with expository and discursive writings on the nature of archival theory and how it can or cannot be distinguished from praxis, little critical attention has been paid until recently to how archival theory has been, or should be built." 49 The research presented here is an exploration of how a new theory of the use of archives-modes of seeing-might emerge from in-depth engagement with experienced users. Their testimony, though not couched in the language of archival principles, shows that people who depend on digitized photograph archives for their livelihood or as a way of engaging in shared, community-driven historical learning can see the archive that thrives digitally through and beyond the screen.

\footnotetext{
${ }^{49}$ Anne Gilliland and Sue McKemmish, "Building an Infrastructure for Archival Research," Archival Science 4 (September 2004): 7.
} 
M O D E S O F

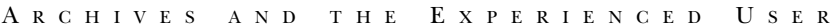

\section{Appendix I: Interview Protocol}

I. Introductions

- Brief background on the project to date

- Equipment setup and consent form

- Outline of interview and methodology

II. Visual Intelligence and Expertise

- Origins of interest in photography-general and specific

- Describe your own expertise as you see it

- Varying areas of expertise

- Acquiring your expertise

- Looking at photographs and digital surrogates-material characteristics (See diagram)

- Looking at digital photographs-your methods

- Specialized knowledge beyond materiality

- Technology tools

- Your working and viewing environment

- Online and print and original

- Other people you know and work with who are experts in your area

III. Decision Making on Your Project

- Origins of the project

- How did the project evolve?

- Your specific tasks in producing the product

- Walk me through a general scenario from search to decision to use a photograph

IV. Choosing and Using Individual Photographs-As Many Examples as Feasible

- Discussion of the visual content of the photograph itself.

- Discussion of decision making criteria for choosing to use the photograph. (See quality factors sheet)

- Importance of various types of cues

- Discussion of technical aspects of the digitized photo. (See rating sheet)

V. Library of Congress Digital Image Collections

- The relative importance of Library of Congress collections to the project

- Your relationship with library, its collections, and staff

- American Memory-pros and cons from your perspective

- Prints and Photos Division-pros and cons from your perspective

- Searching for images-LC tools and others 


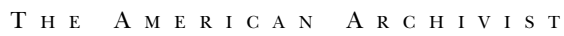

VI. Interview Conclusion

- Loose ends and important issues not yet discussed

- Next steps in the research project 